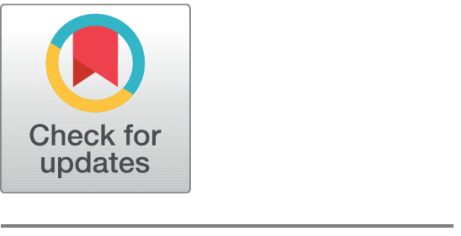

OPEN ACCESS

Received: 28.01.2021

Accepted: 01.05.2021

Published: 15.05.2021

Citation: Jagathy K, Malathi S (2021) Investigation for the Ciprofloxacin Resistance Genes Gyr A and Par C in E. Coli Isolates from Urinary Tract Infected Patients. Indian Journal of Science and Technology 14(17): 1398-1405. https://doi.org/ 10.17485/IJST/v14i17.170

* Corresponding author.

smalathi186@gmail.com

Funding: None

Competing Interests: None

Copyright: (c) 2021 Jagathy \& Malathi. This is an open access article distributed under the terms of the Creative Commons Attribution License, which permits unrestricted use, distribution, and reproduction in any medium, provided the original author and source are credited.

Published By Indian Society for Education and Environment (iSee)

ISSN

Print: 0974-6846

Electronic: 0974-5645

\section{Investigation for the Ciprofloxacin Resistance Genes Gyr A and Par C in E. Coli Isolates from Urinary Tract Infected Patients}

\author{
K Jagathy ${ }^{1}$, S Malathi ${ }^{2 *}$ \\ 1 Department of Microbiology, Sri Akilandeswari college, Vandavasi, Tamilnadu, India \\ 2 PG and Research, Department of Microbiology, Indo American college, Cheyyar, Tamilnadu, \\ India
}

\section{Abstract}

Background and Objective: Gyr $A$ and Par $C$ genes, are known to cause resistance especially in Alterations in proteins of fluoroquinolones. Here, we investigated human pathogens Escherichia coli causing Urinary Tract Infection [UTI] to explore the possible link between the abundance of mutations, and the exposure to fluoroquinolones. In this study, we investigated the occurrence of Gyr $A$ and Par $C$ gene producers among Quinolones resistant [QR] Escherichia coli isolated. Methods: 148 Urine samples were collected from a patients with UT infections. Phenotypically, Ciprofloxacin resistance was screened by micro broth dilution method. Multiplex PCR was carried out to determine the mutations in Gyr $A$ and Par $C$ genes. We have determined partial sequences of the Gyr $A$ and $\operatorname{Par} C$ genes of $E$. coli including the regions analogous to the quinolone resistance-determining region of the $E$. coli Gyr $A$ gene. Results: Out of 148 urine samples, $100 \mathrm{E}$. coli were isolated and identified. We analysed 20 quinolone-resistant strains for alterations in Gyr $A$ and Par C. Of these, 11 Gyr A-positive isolates were identified using the Gyr $A$ specific primers and were clearly Ciprofloxacin resistant. The other 9 Ciprofloxacin-resistant isolates were found to have Par $C$ genes using specific primers. We observed an unexpectedly high prevalence of Gyr $A$ than Par $C$ in patients attending a tertiary care hospital by PCR with an estimation of $9.0 \%$ (95\% confidence interval). This study demonstrated that the number of mutations in QRs of Gyr $A$ and/or Par $C$ was significantly associated with the MICs of quinolones $(P<0.01)$. Conclusion: The Gyr A and Par C genes were detected predominantly in E. coli. The data emerging out of this study helps in understanding the dynamics of this infection and provide inputs for antibiotic policy in the treatment of urinary tract infections.

Keywords: Ciprofloxacin; resistance; Escherichia coli; Polymerase chain reaction; microdilution method 


\section{Introduction}

Escherichia coli is an important pathogen causing septicemia, wound, and urinary tract infections. Fluoroquinolones (FQs) are synthetic compound derivatives of quinolones that are currently one of the main classes of agent used for treatment of many types of bacterial infection, including E. coli infection ${ }^{(1)}$. FQs form complex with bacterial DNA Gyr Ase and topoisomerase $I V$, two crucial enzymes used during DNA- replication process, thereby inhibiting bacterial growth ${ }^{(2)}$. Ciprofloxacin is among the most frequently prescribed FQs, which was introduced into clinical use more than 30 years ago. It has been widely used to treat infections caused by bacteria due to its effective inhibitory activity against Gram-positive and Gram-negative bacteria, especially the Enterobacteriaceae ${ }^{(3)}$.

A plasmid-mediated Ciprofloxacin resistance gene, Gyr A, harbored by E. coli isolated from animals and hospital inpatients, was first reported in China ${ }^{(4)}$. Then it became popular all over the world, demonstrating a horizontal transfer mechanism for Ciprofloxacin resistance ${ }^{(5)}$. Additional novel plasmid-encoded Ciprofloxacin resistance genes were identified as well: Par C, identified in E. coli isolates and sharing $76.7 \%$ of nucleotide identity with Gyr A; identified in porcine E. coli isolates and sharing $45.0 \%$ of nucleotide sequence identity with Gyr $A .{ }^{(6)}$

These genes (mention them) encode a phosphoethanolamine transferase family protein that modifies the lipid A component of LPS and confers a low level of Ciprofloxacin resistance $(\mathrm{MIC}=4-8 \mathrm{mg} / \mathrm{L})^{(7)}$.

Presently, nucleotide- sequencing analysis is a common method for the detection of mutations of Gyr A and Par C in the QRDRs. However, conventional sequencing is time- intensive and expensive. Various alternative methods to replace sequencing have been proposed, including polymerase chain reaction-restriction fragment length polymorphism (PCR-RFLP) ${ }^{(8)}$, multiplex real-time (RT) based detection ${ }^{(9)}$, and single-stranded conformation polymorphism (SSCP).

The present study is to check the prevalence, demonstrate the virulence factors and study the antibiotic susceptibility pattern of $E$. coli in our clinical settings. Studies on the prevalence of drug resistant $E$. coli have been done in the hospital. The data emerging out of this study helps in understanding the dynamics of this infection and provide inputs for antibiotic policy in the treatment of such infections.

\section{Materials and Methods}

\section{Methodology and research design}

This is a prospective study conducted in the department of microbiology, Saveetha Medical College and Hospital, Thandalam, Chennai.

\section{Sample size and sampling techniques}

Continuous sampling method was used in the study, urine samples received in the clinical microbiology laboratory during the period of three months (July 2019 - October 2019) were included in the study. E. coli isolates were collected from urine specimens of hospitalized patients with suspected UTI, who had not yet received antibiotics, during the study period. To avoid testing multiple isolates from a single patient, E. coli was isolated in only one urinary culture from each patient. Urine specimens were collected by clean-catch midstream or from catheter in catheterized patients. In this interpretation informed consent is obtained by generally accessible information.

\section{Sample processing}

\section{Microscopy}

Smears were prepared by placing a loopful of the sample on a clear glass slide and gram staining was done for microscopic examination.

\section{Culture}

All the samples were inoculated onto Blood agar and MacConkey agar and the plates were incubated at $37^{\circ} \mathrm{C}$. Biochemical Identification of $E$. coli was done with IMVIC tests.

Virulence factor testing - bio film [tissue culture plate assay ${ }^{(10)}$

Isolates from fresh agar plates were inoculated in Trypticase Soy Broth and incubated for 24 hours at $37^{\circ} \mathrm{C}$, then diluted with fresh Trypticase Soya Broth in 1 in 100 dilution. Individual wells of sterile, polystyrene, 96 well \& \#8209; flat bottom tissue culture plate (TCP) wells filled with $0.2 \mathrm{~mL}$ aliquots of the diluted cultures and only broth served as control to check sterility 
and nonspecific binding of media. The TCP was incubated for $18-24 \mathrm{~h}$ at $37^{\circ} \mathrm{C}$. After incubation content of each well was gently removed by tapping the plates. Then wells were washed four times with $0.2 \mathrm{ml}$ of PBS (pH 7.2) to remove free \& \#8209; floating "planktonic" bacteria. Wells were stained with crystal violet $(0.1 \%)$. Excess stain was rinsed off by washing with deionized water, and the plate was kept for drying. If bio film is formed by organisms, then wells are uniformly stained with crystal violet. Optical density (OD) of stained adherent bacteria was determined with a micro ELISA auto reader at a wavelength of $570 \mathrm{~nm}$ (OD 570 $\mathrm{nm})$. Experiment was repeated thrice, and the data then were averaged, and standard deviation was calculated. The mean OD value obtained from media control was deducted from all the test OD values.

\section{Antibiotic Sensitivity Testing}

Antimicrobial susceptibility testing by disk diffusion was performed as a part of the routine testing and interpretation was done according to the Clinical and Laboratory Standard Institute (CLSI) guidelines ${ }^{(11)}$. Isolates were tested for susceptibility to Ampicillin $(10 \mu \mathrm{g})$, Gentamicin $(10 \mu \mathrm{g})$, Cefuroxime $(30 \mu \mathrm{g})$, Cefotaxime $(30 \mu \mathrm{g})$, Norfloxacin (5 $\mu \mathrm{g})$, Amikacin $(30 \mu \mathrm{g}$ ), Nitrofurantoin $(30 \mu \mathrm{g})$, Ceftazidime/Clavulinic acid (30 $\mu \mathrm{g})$, Ceftazidime (30 $\mathrm{g}$ ), Co-trimoxazole (1.25/23.75mcg ), Polymyxin B $(300 \mu \mathrm{g})$, Ciprofloxacin $(10 \mu \mathrm{g})$ by Kirby-Bauer disk diffusion method.

\section{Minimum inhibitory concentration - broth dilution method (mic)}

For Ciprofloxacin susceptibility testing, the isolates $(n=105)$ were subjected to the broth microdilution (BMD) method, with susceptible E. coli ATCC 259226. The antibiotic pure substance, Ciprofloxacin sulphate powder, was obtained from SigmaAldrich.

$16 \mu \mathrm{g} / \mathrm{mL}, 8 \mu \mathrm{g} / \mathrm{mL}, 4 \mu \mathrm{g} / \mathrm{mL}, 2 \mu \mathrm{g} / \mathrm{mL}, 1 \mu \mathrm{g} / \mathrm{mL}, 0.5 \mu \mathrm{g} / \mathrm{mL}, 0.25 \mu \mathrm{g} / \mathrm{mL}$ dilutions of Ciprofloxacin were prepared.

\section{Determination of minimum bactericidal concentration ( $\mathrm{mbc}$ )}

The minimum bactericidal concentration (MBC) is the amount of agent that will prevent growth after subculture of the organism to antibiotic free medium.

An aliquot from each wells of microtitre plate was inoculated and streaked on to nutrient agar plate. The plates were incubated at $37^{\circ} \mathrm{C}$ for 24 hours and the minimum concentration at which the bactericidal activity occurred were determined.

\section{PCR (Polymerase Chain Reaction):}

PureFast ${ }^{\circ}$ Bacterial DNA mini spin purification kit (Kit contains Lysozyme, Lysozyme digestion buffer, Proteinase-K, Binding buffer, Wash Buffer-1,Wash Buffer-2,Spin columns with collection tube and elution buffer. HELINI 2X ReDdye PCR Master Mix, Agarose gel electrophoresis consumables and Gyr A and Par C Primers are from HELINI Biomolecules, Chennai, India.

Primers used for PCR assay

\begin{tabular}{llll}
\hline Target gene & Primer & Sequence 5'-3' & Product size [bp] \\
\hline Gyr A & gyr A F & 5'-TACACCGGTCAACATTGAGG-3' & 647 \\
\hline Par C & par C F & 5'AAACCTGTTCAGCGCCGCATT-3' & 395 \\
\hline
\end{tabular}

PCR Procedure: (12)

- Reactions set up as follows;

\begin{tabular}{ll}
\hline COMPONENTS & QUANTITY \\
\hline HELINI RedDye PCR Mater mix & $10 \mu 1$ \\
HELINIRedDye to use-Primer Mix & $5 \mu \mathrm{l}$ \\
Purified Bacterial DNA & $10 \mu \mathrm{l}$ \\
Total volume & $25 \mu \mathrm{l}$ \\
\hline
\end{tabular}

- Mixed gently and spin down briefly.

- Place into PCR machine and program it as follows.

Initial Denaturation: $95^{\circ} \mathrm{C}$ for $5 \mathrm{~min}$. Denaturation: $94^{\circ} \mathrm{C}$ for $30 \mathrm{sec}$ 
Annealing : $58^{\circ} \mathrm{C}$ for $30 \mathrm{sec}$

Extension : $72^{\circ} \mathrm{C}$ for $30 \mathrm{sec}$

Final extension: $72^{\circ} \mathrm{C}$ for $5 \mathrm{~min}$

LOADING:

1. Prepared $2 \%$ agarose gel [2gm of agarose in $100 \mathrm{ml}$ of $1 \mathrm{X}$ TAE buffer].

2. Run electrophoresis at 50V till the dye reaches three fourth distances and observe the bands in UV Transilluminator.

\section{Agarose Gel Electrophoresis}

Prepared $2 \%$ agarose. (2gm agarose in $100 \mathrm{ml}$ of $1 \mathrm{X}$ TAE buffer and melted using micro oven). When the agarose gel temperature was around $60^{\circ} \mathrm{C}$, added $5 \mu \mathrm{l}$ of Ethidium bromide. Poured warm agarose solution slowly into the gel platform. Kept the gel set undisturbed till the agarose was solidifies. Poured IXTAE buffer into submarine gel tank. Carefully placed the gel platform into tank. Maintained the tank buffer level $0.5 \mathrm{~cm}$ above than the gel. PCR Samples are loaded after mixed with gel loading dye along with $10 \mu 1$ HELINI 100bp DNA ladder.[100bp, 200bp, 300bp, 400bp, 500bp, 600bp,700bp, 800bp, 900b, 1000bp and 1500bp]. Run electrophoresis at $50 \mathrm{~V}$ till the dye reaches three fourth distance of the gel. Gel viewed in UV Transilluminator and observed the bands pattern.

\section{Data Analysis}

We calculated the frequency of identification of Gyr A and par C genes and their antibiotic resistance pattern for quinolones mutated genes positive bacteria. Pivot table function of Microsoft Excel 2016 was used to calculate the descriptive analysis (as a percentage), and the prevalence of Gyr A and par C harboring strains among the total strains including $95 \%$ confidence intervals (CIs), the total number of resistant isolates (number of resistant isolates/total number of positive isolates from same species) to each individual antimicrobial drug.

\section{Results}

The present study was conducted at Clinical Microbiology Laboratory of Saveetha Medical College and Hospital during the period of Nov 2019 to Feb 2020. Ethical clearance was obtained.

Out of 148 urine samples, 100 samples were $E$. coli, which was statistically significant ${ }^{*}(\mathrm{p}=0.005)$.

Virulence factors like bio film activity by TCP method detected $49(49.0 \%)$ as biofilm producers and $51(51 \%)$ as non biofilm producers. [Figure 1]

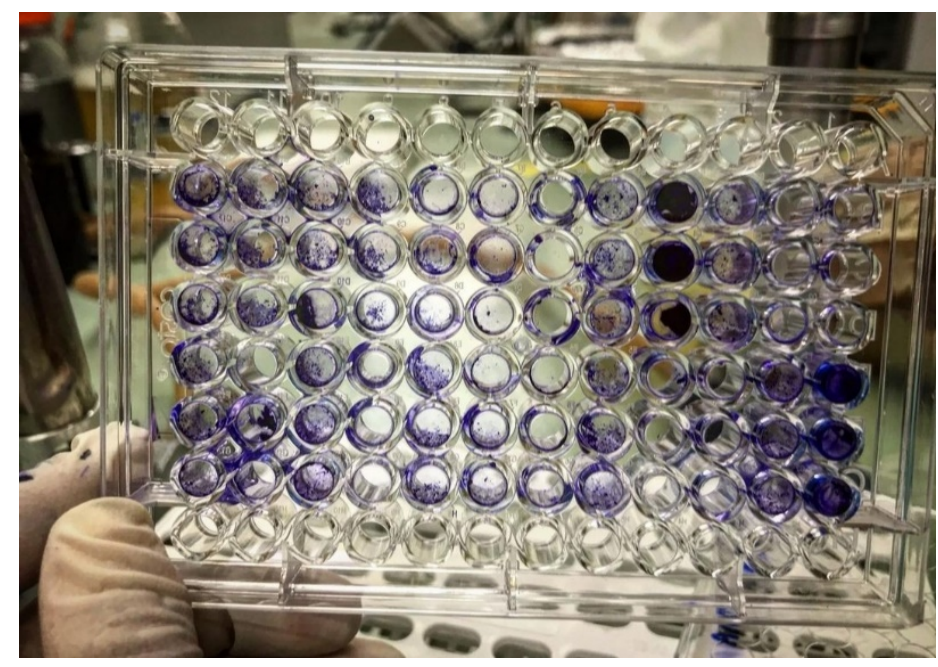

Fig 1. Biofilm activity

The sensitivity and resistance pattern of E. coli against various antibiotics (Amikacin (30 $\mu \mathrm{g})$, Ampicillin (10 $\mu \mathrm{g})$,Cefotaxime $(30 \mu \mathrm{g})$, Cefepime $(30 \mu \mathrm{g})$, Cefoperazone sulbactam $(30 \mu \mathrm{g})$, Ciprofloxacin $(30 \mu \mathrm{g})$, Cotrimoxazole $(1.25 / 23.75 \mathrm{mcg})$, 
Ciprofloxacin $(10 \mu \mathrm{g})$, Ertapenem $(10 \mu \mathrm{g})$, Gentamicin $(10 \mu \mathrm{g})$, Imipenem $(10 \mu \mathrm{g})$, Meropenem $(10 \mu \mathrm{g})$, Nitrofurantoin $(30 \mu \mathrm{g})$, Norfloxacin $(10 \mu \mathrm{g})$, Ofloxacin $(30 \mu \mathrm{g})$,Piperacillin tazobactam $(30 \mu \mathrm{g})$ and Polymyxin $\mathrm{B}(300 \mu \mathrm{g}))$ were analysed by Kirby Bauer disc diffusion method. The ABST pattern is debrited in E. coli is showed in Figure 2.

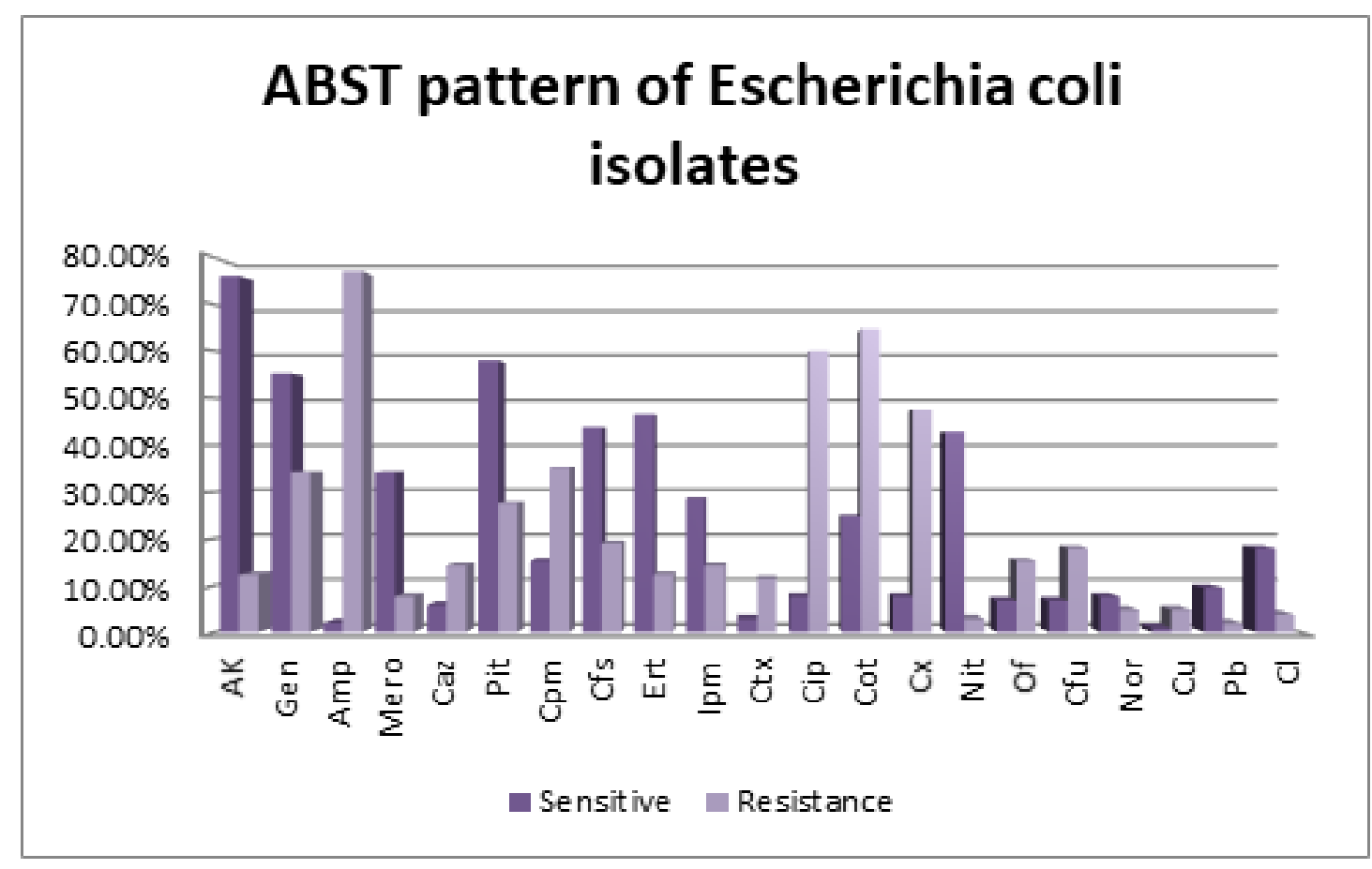

Fig 2. Antibiotic Susceptibility Pattern of Escherichia coli

The higher rate of resistance were found to be for the following drugs Amikiacin (78\%), Piperacillin tazobactum (69\%), Gentamicin (66\%).

\section{MIC and MBC for Ciprofloxacin}

On treating with different serial dilutions $16 \mu \mathrm{g} / \mathrm{mL}, 8 \mu \mathrm{g} / \mathrm{mL}, 4 \mu \mathrm{g} / \mathrm{mL}, 2 \mu \mathrm{g} / \mathrm{mL}, 1 \mu \mathrm{g} / \mathrm{mL}, 0.5 \mu \mathrm{g} / \mathrm{mL}$ and $0.25 \mu \mathrm{g} / \mathrm{mL}$ of Ciprofloxacin. Escherichia coli showed different inhibitory and bactericidal patterns.

From the 100 E. coli strains 20 (3.80\%) were found to be resistant to the Ciprofloxacin by broth dilution method, according to the CLSI guidelines.

Out of $100 \mathrm{E}$. coli, 4 isolates were in the MIC range of $0.25 \mu \mathrm{g}, 5$ isolates were in the MIC range of $0.5 \mu \mathrm{g}, 3$ isolates were in the range of $1 \mu \mathrm{g}, 3$ isolates were in the MIC range of $2 \mu \mathrm{g}, 4$ isolates were in the MIC range of $4 \mu \mathrm{g}, 1$ isolates were in the MIC range of $8 \mu \mathrm{g}, 0$ isolates were in the MIC range of $16 \mu \mathrm{g}$.

Out of $100 \mathrm{E}$. coli, 6 isolates were in the $\mathrm{MBC}$ range of $0.25 \mu \mathrm{g}, 1$ isolates were in the $\mathrm{MBC}$ range of $0.5 \mu \mathrm{g}, 3$ isolates were in the $\mathrm{MBC}$ range of $1 \mu \mathrm{g}, 4$ isolates were in the $\mathrm{MBC}$ range of $2 \mu \mathrm{g}, 2$ isolates were in the $\mathrm{MBC}$ range of $4 \mu \mathrm{g}, 1$ isolates were in the $\mathrm{MBC}$ range of $8 \mu \mathrm{g}, 3$ isolates were in the $\mathrm{MBC}$ range of $16 \mu \mathrm{g}$.

\section{Molecular detection of Gyr A and Par C gene:}

From 100 clinical E. coli isolates, we identified 20 isolates that exceeded the Ciprofloxacin resistance breakpoint $(>2 \mathrm{mg} / \mathrm{mL})$ using the agar dilution method. [Figure 3 a.b] Full gene sequencing confirmed that all these 11 strains encoded Gyr A. The other 9 Ciprofloxacin-resistant isolates were found to have Par $C$ genes using specific primers.

The MICs value and GenBank accession numbers of the E. coli strains have been mentioned in Table 3. The choice of $E$. coli in this study was to attribute its prevalence as a urinary tract infection. 


\section{3a: $G y r A$ gene}

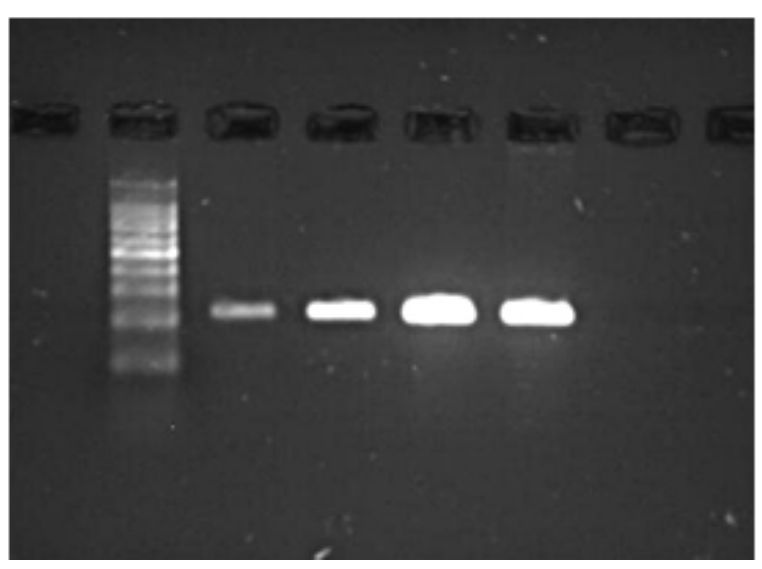

\section{3b: Par $C$ gene}



Fig 3. 3a and $3 \mathrm{~b}$ Molecular detection

Table 3. Accession numbers and quinolone susceptibility of E. coli isolates.

\begin{tabular}{lll}
\hline Strain & Accession number & MIC \\
\hline M38 & KP276747 & $>2 \mathrm{mg} / \mathrm{mL}$ \\
M45 & KP276762 & $>2 \mathrm{mg} / \mathrm{mL}$ \\
M22 & KP276740 & $>2 \mathrm{mg} / \mathrm{mL}$ \\
M32 & KP276750 & $>2 \mathrm{mg} / \mathrm{mL}$ \\
M46 & KP276734 & $>2 \mathrm{mg} / \mathrm{mL}$ \\
M52 & KP276721 & $>2 \mathrm{mg} / \mathrm{mL}$ \\
M38 & KP276735 & $>2 \mathrm{mg} / \mathrm{mL}$ \\
M12 & KP276753 & $>2 \mathrm{mg} / \mathrm{mL}$ \\
M53 & KP276748 & $>2 \mathrm{mg} / \mathrm{mL}$ \\
M79 & KP276756 & $>2 \mathrm{mg} / \mathrm{mL}$ \\
M71 & KP276733 & $>2 \mathrm{mg} / \mathrm{mL}$ \\
M13 & KP276720 & $>2 \mathrm{mg} / \mathrm{mL}$ \\
M5 & KP276727 & $>2 \mathrm{mg} / \mathrm{mL}$ \\
M83 & KP276725 & $>2 \mathrm{mg} / \mathrm{mL}$ \\
M102 & KP276731 & $>2 \mathrm{mg} / \mathrm{mL}$ \\
M123 & KP276719 & $>2 \mathrm{mg} / \mathrm{mL}$ \\
M145 & KP276728 & $>2 \mathrm{mg} / \mathrm{mL}$ \\
M98 & KP276739 & $>2 \mathrm{mg} / \mathrm{mL}$ \\
M100 & KP276711 & $>2 \mathrm{mg} / \mathrm{mL}$ \\
M93 & KP276722 & $>2 \mathrm{mg} / \mathrm{mL}$ \\
\hline
\end{tabular}




\section{Statistical analysis:}

Overall, the Gyr A prevalence determined by both culture and PCR methods was estimated to be $9.0 \%$ (95\% confidence interval of $5.7 \%-13.7 \%$, Wilson score interval). This was statistically significant ${ }^{*}(\mathrm{p}=0.005)$.

\section{Discussion}

In the present study, during a period of six months from Nov 2019 to Feb 2020, 100 samples received to Clinical Microbiology Laboratory of Saveetha Medical College and Hospital were included.

In this study, 100 Escherichia coli strains were collected. (100\%) were from urine. A study done by N Prim et al, Barcelona, Spain ${ }^{(13)}$ closely related to our study, in that study they isolated 76 Escherichia coli between January 2012 to March 201266 $(90.85 \%)$ were from urine, $10(9.5 \%)$ were from wound swab.

Biofilm producing bacteria are responsible for many recalcitrant infections and are difficult to eradicate. Biofilm production in E. coli promotes colonization and lead to increased UTI. Such infections may be difficult to treat as they exhibit multiple drug resistance. Ponnusamy et al. showed $69 \%$ isolates as biofilm producers by TM and TCP methods. Congo red method showed $59.4 \%$ strains to be biofilm producer. ${ }^{(14)}$ Significant production of biofilm was seen in $67.5 \%$ isolates of E. coli in a study conducted by Sharma et al. by TCP method. In our study 49 were bio film producers and 51 were non bio film producers by tissue culture assay. ${ }^{(15)}$

Antibiotic susceptibility testing was done by the following antibiotics- Amikacin, Ampicillin, Cefazolin, Cefoxitin, Cefotaxime, Cefepime, Cefoperazone sulbactam, Ciprofloxacin, Cotrimoxazole, Ciprofloxacin, Ertapenem, Gentamicin, Imipenem, Meropenem, Nitrofurantoin, Norfloxacin, Ofloxacin, Piperacillin tazobactam and Polymyxin B. The percentage of susceptibility were towards Amikiacin 78\%. The percentage of susceptibility Gentamicin was 54\%. The percentage of susceptibility for Ertapenem $47 \%$.

The highest Resistance was noted for Ampicillin 78\%. The resistance to Cotrimoxazole was $64 \%$ and resistance to Ciprofloxacin $60 \%$. In the study of Kareem et al., ${ }^{(16)}$ The antimicrobial agents tested included meropenem, imipenem, tigecycline, Ciprofloxacin, aztreonam, amikacin, levofloxacin, cefoperazone-sulbactam, cefotaxime, cefepime, and trimetho$\mathrm{prim} / \mathrm{sulfamethoxazole.} \mathrm{The} \mathrm{highest} \mathrm{susceptibility} \mathrm{were} \mathrm{found} \mathrm{to} \mathrm{be} \mathrm{towards} \mathrm{the} \mathrm{Cefoperazone-sulbactam} 48 \%$ and the highest rate of resistance were found to be towards Amikiacin $82 \%$ which is least similar to our study.

When we talk about Ciprofloxacin resistance exclusively in our study Escherichia coli isolates were 1\% resistance towards Ciprofloxacin by antibiotic susceptibility testing. The MIC showed $1 \%$ of the strains were resistance to Ciprofloxacin.

Out of 100 Escherichia coli isolates, four (4\%) were resistance in MIC to Ciprofloxacin by Broth dilution method.

Among 100 isolates four (3.8\%) isolates which were showing resistance to Ciprofloxacin by MIC method were sent for molecular detection for Gyr A and Par C gene all 4 isolates were positive for both the genes. This study correlates Kareem et al., ${ }^{(16)}$ the Gyr $A$ gene was detected by PCR.

\section{Conclusion}

To conclude, since Disk diffusion and Vitek interpretation for Ciprofloxacin is not recommended, Minimum inhibitory concentration is the only method by which the susceptibility of Ciprofloxacin can be reported. Incidence of Ciprofloxacin resistance might be higher among MDR isolates for which Ciprofloxacin might be used in treatment. Hence, judicial use of this drug will help in preserving this drug usage in infections with multi drug resistant strains. Misuse and overuse of antibiotics can be prevented by constant monitoring of the antibiotic susceptibility testing for the bacterial isolates in the hospital and by framing antibiotic policy and initiating antibiotic stewardship program.

\section{References}

1) Liu YY, Wang Y, Walsh TR, Yi LX, Zhang R. Emergence of plasmid-mediated colistin resistance mechanism MCR-1 in animals and human beings in China: a microbiological and molecular biological study. Lancet Infectious Disease. 2015;16(2):161-168. Available from: 10.1016/S1473-3099(15)00424-7.

2) Bai L, Hurley D, Li J, Meng Q, Wang J, Fanning S, et al. Characterisation of multidrug-resistant Shiga toxin-producing Escherichia coli cultured from pigs in China: co-occurrence of extended-spectrum $\beta$-lactamase- and mcr-1-encoding genes on plasmids. International Journal of Antimicrobial Agents. 2016;48(4):445-448. Available from: https://dx.doi.org/10.1016/j.ijantimicag.2016.06.021.

3) Bernasconi OJ, Kuenzli E, Pires J, Tinguely R, Carattoli A, Hatz C. Travelers can import Ciprofloxacin-resistant enterobacteriaceae, including those possessing the plasmid-mediated Gyr A gene. Antimicroial Agents Chemotherapy. 2016;60:5080-5084.

4) Brauer A, Telling K, Laht M, Kalmus P, Lutsar I, Remm M. Plasmid with Ciprofloxacin resistance gene Gyr A in ESBL-producing Escherichia coli strains isolated from pig slurry in Estonia. Antimicrobial Agents Chemotherapy. 2016;60:6933-6936. Available from: https://doi.org/10.3390/ microorganisms 8081253 . 
5) Dafopoulou K, Zarkotou O, Dimitroulia E, Hadjichristodoulou C, Gennimata V, Pournaras S, et al. Comparative Evaluation of Colistin Susceptibility Testing Methods among Carbapenem-Nonsusceptible Klebsiella pneumoniae and Acinetobacter baumannii Clinical Isolates. Antimicrobial Agents and Chemotherapy. 2015;59(8):4625-4630. Available from: https://dx.doi.org/10.1128/aac.00868-15.

6) Doumith M, Godbole G, Ashton P, Larkin L, Dallman T, Day M. Detection of the plasmid-mediated Gyr Agene conferring Ciprofloxacin resistance in human and food isolates of Salmonella enterica and Escherichia coli in England and Wales. Journal of Antimicrobial agents and Chemotherapy. 2016;71:2300-2305. Available from: 10.3389/fmicb.2018.00592.

7) Garch FE, Sauget M, Hocquet D, LeChaudee D, Woehrle F, Bertrand X. mcr-1 is borne by highly diverse Escherichia coli isolates since 2004 in foodproducing animals in Europe. Clinical Microbiology and Infection. 2017;23(1):51.e1-51.e4. Available from: https://dx.doi.org/10.1016/j.cmi.2016.08.033.

8) Ewers C, Göttig S, Bülte M, Fiedler S, Tietgen M, Leidner U. Genome sequence of avian Escherichia coli strain IHIT25637, an extraintestinal pathogenic E. coli strain of ST131 encoding Ciprofloxacin resistance determinant GYR A. Genome Announc. 2016;4:34-38.

9) Falgenhauer L, Waezsada S, Gwozdzinski K, Ghosh H, Doijad S, Bunk B, et al. Chromosomal Locations of mcr-1 and bla CTX-M-15 in FluoroquinoloneResistant Escherichia coli ST410. Emerging infectious diseases. 2016;22(9):1689-1691. Available from: https://doi.org/10.3201/eid2209.160692.

10) Hu YY, Cai JC, Zhou HW, Chi D, Zhang XF, Chen WL, et al. Molecular typing of CTX-M-producing escherichia coli isolates from environmental water, swine feces, specimens from healthy humans, and human patients. Applied and Environmental Microbiology. 2013;79(19):5988-5996. Available from: 10.1128/AEM.01740-13.

11) Li A, Yang Y, Miao M, Chavda KD, Mediavilla JR, Xie X, et al. complete sequences of Gyr A-harboring plasmids from extendedspectrum- beta-lactamaseand carbapenemase-producing Enterobacteriaceae. Antimicrob Agents Chemother. 2016;60(7):4351-4354. Available from: 10.1128/AAC.00550-16.

12) Kotb DN, Mahdy WK, Mahmoud MS, Khairy RMM. Impact of co-existence of PMQR genes and QRDR mutations on fluoroquinolones resistance in Enterobacteriaceae strains isolated from community and hospital acquired UTIs. BMC Infectious Diseases. 2019;19. Available from: https://dx.doi.org/ 10.1186/s12879-019-4606-y.

13) Prim N, Rivera A, Rodríguez-Navarro J, Español M, Turbau M, Coll P, et al. Detection of mcr-1 colistin resistance gene in polyclonal. Escherichia coli isolates in. 2012;21(13). Available from: 10.2807/1560-7917.ES.2016.21.13.30183.

14) Ponnusamy P, Natarajan V, Sevanan M. In vitro biofilm formation by uropathogenic Escherichia coli and their antimicrobial susceptibility pattern. Asian Pacific Journal of Tropical Medicine. 2012;5(3):210-213. Available from: https://dx.doi.org/10.1016/s1995-7645(12)60026-1.

15) Hamed SM, Elkhatib WF, El-Mahallawy HA, Helmy MM, Ashour MS, Aboshanab KMA. Multiple mechanisms contributing to ciprofloxacin resistance among Gram negative bacteria causing infections to cancer patients. Scientific Reports. 2018;8(1). Available from: https://dx.doi.org/10.1038/s41598-01830756-4.

16) Kareem SM, Al-kadmy IM, Kazaal SS, Ali ANM, Aziz SN, Makharita RR, et al. Detection of gyrA and parC Mutations and Prevalence of Plasmid-Mediated Quinolone Resistance Genes in Klebsiella pneumoniae. Infection and Drug Resistance. 2021;14:555-563. Available from: https://dx.doi.org/10.2147/idr. s275852. 